\title{
Self-regulatory fatigue in chronic multisymptom illnesses: scale development, fatigue, and self-control
}

This article was published in the following Dove Press journal: Journal of Pain Research

5 March 2013

Number of times this article has been viewed

\author{
Lise Solberg Nes 1,3 \\ Shawna L Ehlers' \\ Mary O Whipple ${ }^{2}$ \\ Ann Vincent ${ }^{2}$
}

'Department of Psychiatry and Psychology, Mayo Clinic, Rochester, MN, USA; ${ }^{2}$ Fibromyalgia and Chronic Fatigue Clinic, General Internal Medicine, Mayo Clinic, Rochester, MN, USA; ${ }^{3}$ Center for Shared Decision Making and Collaborative Care Research, Oslo University Hospital, Oslo, Norway
Correspondence: Lise Solberg Nes Department of Psychiatry and Psychology, Mayo West II, 200 First Street SW, Rochester, MN 55905, USA

Tel +I 5072845849

Fax +I 5072844158

Email solbergnes@msn.com
Background: Self-regulatory capacity involves ability to regulate thoughts, emotions, and behavior. Chronic multisymptom illnesses such as fibromyalgia and chronic fatigue syndrome are accompanied by numerous challenges, and have recently been associated with self-regulatory fatigue (SRF). Chronic multisymptom illnesses are also frequently associated with physical fatigue, and through development of a scale measuring SRF, the current study aimed to examine how SRF can be distinguished from physical fatigue. The study also sought to distinguish SRF from self-control.

Methods: Two self-regulation researchers developed 30 items related to self-regulatory capacity. These items were distributed to patients $(n=296)$ diagnosed with chronic multisymptom illness together with validated measures of physical fatigue and self-control. A principal factor analysis was employed to examine factor structures, identify inter-item relationships, and aid in scale development.

Results: The final proposed scale consisted of 18 items measuring self-regulatory capacity (SRF-18) with cognitive, emotional, and behavioral SRF components. Internal consistency and reliability was acceptable (Cronbach's $\alpha=0.81$ ). The final scale was moderately correlated with self-control $(r=-0.48)$ and highly correlated with physical fatigue $(r=0.75)$, although more so with emotional $(r=0.72)$ and mental $(r=0.65)$ than physical $(r=0.46)$ fatigue components.

Conclusion: The current study suggests a new scale for measurement of SRF in chronic multisymptom illness. Although cross-validation studies are necessary, such a scale may contribute to a better understanding of the concept of self-regulation and the role of SRF in chronic illness. Although related to physical fatigue and self-control, the results point to SRF as a distinct construct.

Keywords: self-regulation, chronic multisymptom illness, fibromyalgia, chronic fatigue syndrome

\section{Introduction}

The ability to self-regulate entails the capacity to control or alter thoughts, feelings, and behavior. Chronic multisymptom illnesses such as fibromyalgia and chronic fatigue syndrome have multifaceted interactions and dysregulations in cognitive, emotional, behavioral, and physiological domains. Coping with and adjusting to these illnesses can be taxing, and successful adaptation may depend on each person's ability to self-regulate. However, self-regulatory capacity appears to be a limited resource, and recent research indicates that patients with chronic multisymptom illnesses may be more prone to selfregulatory fatigue (SRF) compared with pain-free controls. ${ }^{1,2}$ Fatigue of self-regulatory resources, perhaps even chronic SRF, may lead to further difficulties coping with day to day challenges and activities for patients with chronic illness. The current study sought 
to develop a scale gauging SRF in chronic multisymptom illness, and to show that SRF is a related yet distinct construct from physical fatigue and self-control.

\section{Self-regulation and SRF}

Self-regulation refers to any ability to control or change reactions and behavior, ${ }^{1,3,4}$ and can involve cognitive processes, such as the ability to control thoughts and impulses, set goals, and make decisions, ${ }^{5}$ emotional processes, such as being able to regulate moods or feelings; ${ }^{5}$ and more behavioral or physiological processes, such as the capacity to activate and get ready for fight or flight, or ability to quiet down, relax, and replenish resources. ${ }^{2,5,6}$ In essence, self-regulation involves capacity to control, guide, manage, or change thoughts, emotions, or behavior. An abundance of research over the past decade has shown that the ability to self-regulate is a variable and limited resource that might be depleted or fatigued. ${ }^{1,2,6,9}$ Self-regulatory efforts such as inhibiting urges, making decisions, or suppressing thoughts or emotions have, for example, been associated with a decreased ability to persist with subsequent tasks, an effect known as self-regulatory "ego" depletion, ${ }^{1}$ or SRF.

\section{Self-regulation and chronic multisymptom illness}

The demands of chronic multisymptom illnesses such as fibromyalgia and chronic fatigue syndrome cross biopsychosocial boundaries, and these conditions are frequently accompanied by cognitive (ie, worry and rumination about health and the future), emotional (ie, distress, anxiety, and depression), and behavioral (eg, passive coping and difficult interpersonal interactions) challenges, all of which could indicate the presence of SRF, as reviewed by Solberg Nes et al. ${ }^{10}$ A recent experimental study supported this notion, because patients diagnosed with fibromyalgia or temporomandibular disorders showed less ability to persist with demanding experimental tasks following self-regulatory effort compared with matched pain-free controls, indicating higher $\mathrm{SRF}^{2}$ In essence, selfregulatory demands may be connected to symptoms or selfregulatory deficits seen in chronic multisymptom illness, and the many challenges presented by chronic multisymptom illness may in fact drain self-regulatory resources.

\section{Self-regulatory fatigue, physical fatigue, and self-control}

The concept of fatigue has wide ranging aspects, but generally refers to physical tiredness or exhaustion. Fatigue of self-regulatory resources, or SRF, can be expected to overlap with physical fatigue, particularly in populations with chronic multisymptom illness or other chronic or taxing illnesses. However, there are indications that SRF predicts impact above and beyond traditional factors such as physical fatigue. For example, the impact of SRF in chronic multisymptom illness has been seen to be mediated by pain, but not by other factors, such as psychological distress, physical fatigue, or baseline physiological differences, ie, heart rate variability, cortisol, or blood glucose. ${ }^{2}$ Similarly, in patients preparing for hematopoietic stem cell transplant, SRF has been incrementally associated with decreased quality of life, use of avoidance coping strategies, and decreased adherence with physicians' recommendations after controlling for pain severity, physical fatigue, and depression. ${ }^{11}$ These findings support the notion that patients with taxing illnesses such as chronic multisymptom illness and hematologic malignancy may in fact suffer from SRF, perhaps chronically so, above and beyond the effects of traditional factors such as physical fatigue.

The concept of self-regulation entails or overlaps with self-control, and the terms of self-regulation or depletion and self-control are at times even used interchangeably. Like self-control, self-regulatory resources likely involve state as well as trait capacity, both with associations to impulsivity and persistence. However, whereas SRF in healthy populations can be predicted to impact short-term tasks intermittently (eg, work, school, exercise, dieting) that depend on self-control and impulse control, SRF in populations with chronic illness likely has a more persistent, profound, and wide ranging impact, as reviewed by Solberg Nes et al, ${ }^{10}$ and may possibly be linked to self-control, particularly trait self-control, to a lesser degree.

\section{Current study}

Self-regulatory capacity or fatigue has so far mainly been measured through experimental (ie, laboratory) tasks, usually involving two consecutive, seemingly unrelated tasks of self-control. ${ }^{1}$ A few studies have aimed to develop specific self-regulation scales. For example, the self-regulation questionnaire $^{12}$ sought to measure self-regulation in the form of ability to develop, implement, and maintain planned behavior, focusing on goal achievement, eg, 'I'm usually careful not to overdo it when I'm working, eating, drinking" and "I have a hard time setting goals for myself." The State Ego Depletion Scale ${ }^{13}$ is another scale related to self-regulation, and seeks to measure state resource depletion in college undergraduates, eg, "Right now, it would take a lot of effort for me to concentrate on something" and "I can't absorb any 
more information." SRF has also been measured by identifying and extracting items related to self-regulatory control and fatigue in existing psychological scales gauging adjustment and well-being. ${ }^{11}$

However, to our knowledge, no established or widely used scale measuring SRF exists at this point, and no scale has so far measured self-regulatory resources in chronic multisymptom illness. The purpose of the current study was to develop and validate a new scale index of general selfregulatory capacity, and to examine whether such a scale can establish SRF as a construct distinct from physical fatigue and self-control in populations with chronic multisymptom illnesses and similar or related taxing conditions.

\section{Materials and methods Procedure overview}

This study was approved by the Mayo Clinic institutional review board. By thorough examination of the existing literature on self-regulation, ${ }^{1-10,14}$ a total of 30 items were developed reflecting aspects of self-regulatory capacity. The focus at this stage was on identifying items reflecting general self-regulatory capacity in terms of cognitive, emotional, and behavioral aspects of self-regulation. All items were on a five-point Likert scale ( $1=$ strongly disagree and $5=$ strongly agree). This initial scale was then administered to a large sample of patients who had previously been diagnosed with fibromyalgia, chronic fatigue syndrome, or both.

Given the noted links and overlap between SRF, selfcontrol, and physical fatigue, the new 30-item scale was distributed together with existing validated scales reflecting self-control and physical fatigue in order to examine convergent validity and differentiate the scale from associated constructs. A validated, unrelated scale of dispositional optimism was also included in order to examine discriminant validity.

\section{Participants}

All measures (a total of 80 items) were mailed to a sample of 1000 patients previously seen in the Mayo Fibromyalgia and Chronic Fatigue Clinic (ie, between 2001 and 2004) who had consented to be a part of a larger study described elsewhere. ${ }^{15-17}$ Surveys were only mailed once and no reminder surveys or reminder phone calls were utilized in the study. Of the 1000 surveys mailed, 296 were completed and returned, 35 patients indicated they did not wish to participate, and 84 surveys were returned to sender due to an incorrect address. Participants $(n=296)$ were aged $21-83$ (median 54) years and $93.6 \%$ were female. The majority of participants were Caucasian (87.8\%), 0.7\% were Black, 1\% reported ethnicity as "other," and $10.5 \%$ of participants did not report ethnicity.

\section{Measures}

\section{Brief Self-Control Scale}

The Brief Self-Control Scale ${ }^{18}$ is a one-item abbreviation of the 36-item Self-Control Scale ${ }^{18}$ which aims to measure five domains of self-control, including controlling thoughts, emotions, impulses, regulating behavior/performance, and breaking habits (eg, "I am lazy," "People would say that I have iron self-discipline," and "I am able to work effectively toward long-term goals"). Items are scored on a five-point Likert scale (1-5). The Brief Self-Control Scale has acceptable internal reliability at $\alpha=0.83-0.85$ and test-retest reliability at $r=0.87 .^{18}$

\section{Multidimensional Fatigue Symptom Inventory: Short Form}

The Multidimensional Fatigue Symptom Inventory: Short Form (MFSI-SF) ${ }^{19}$ is a 30 -item short form of the MFSI, ${ }^{20}$ yielding only scores for the empirically derived subscales of the MFSI. The MFSI-SF is designed to assess principal manifestations of fatigue, including general, physical, emotional, and mental manifestations, as well as vigor, which is an estimate of the patient's energy level, eg, "I feel lively," "My muscles ache," "I am worn out," and "I feel refreshed." Items are scored on a five-point Likert scale (0-4). Research suggests that the MFSI-SF has acceptable psychometric properties (internal consistency $\alpha>0.70$, reliability $r>0.70){ }^{19}$

\section{Life Orientation Test-Revised}

Dispositional optimism was measured using the Life Orientation Test-Revised (LOT-R), ${ }^{21}$ a 10-item measure of generalized positive outcome expectancies. In this questionnaire, three items are phrased positively ("In uncertain times, I usually expect the best"), three negatively ("If something can go wrong for me it will"), and four are filler items that do not contribute to the total optimism score. Items are scored on a five-point Likert scale (1-5). The LOT-R has acceptable internal consistency $(0.78)$ and construct validity with regard to related constructs. ${ }^{21}$

\section{Statistical analyses}

A principal factor analysis with oblique rotation ${ }^{22,23}$ was employed to examine possible factor structures and identify specific items for a new scale measuring and reflecting 
self-regulatory capacity or fatigue. Factor loadings of $r=0.7$ or above are generally considered high, while loadings of $r=0.4$ or below are generally considered lower. ${ }^{22}$ In the current study, we excluded items that loaded with less than $r=0.4$ on any factor. Items with weak loadings (ie, $r<0.4)$ and items that were highly correlated (ie, indicating item redundancy) were discarded. In addition to examining internal consistency via Cronbach's $\alpha$ for the final scale, further evidence for the validity of the scale was examined via correlations with the relevant instruments related to physical fatigue, self-control, and dispositional optimism.

\section{Results}

Factor analysis of the initial 30 items, including further analysis with examination of the scree plot and the pattern matrix, indicated a unidimensional construct. Five items (ie, "I worry and ruminate a lot about my life," "I find it difficult to pay attention," "I feel relaxed," "I feel so restless I can't do anything," and "I remain calm in tense situations") had loadings less than 0.4 and were discarded from further analysis. The remaining 25 items loaded with a Cronbach's $\alpha=0.91$, suggesting high internal consistency and reliability. However, such a high alpha reliability may indicate redundant items, ${ }^{24}$ and further examination of the items revealed high correlations (ie, 0.6 or higher) between some of the remaining items. Seven items (ie, "I feel like giving up on tasks or scheduled events," "I have difficulties concentrating," "I find it easy to organize and plan my days and activities," "Everything I do is an effort," "I'm having a hard time keeping up with all my appointments," "I'm feeling blocked in doing things," and "I feel nervous and restless") with high correlations to other scale items but lower factor loadings than related items were subsequently removed from the scale.

The final scale contained 18 items (SRF-18; see Table 1). Internal consistency reliability for the scale was $\alpha=0.81$, demonstrating an adequate level of reliability. ${ }^{24}$ The obtainable score range for the final scale was 18-90, with higher numbers reflecting higher SRF. The final scale could also be seen as having three subscales, with six items related to cognitive control $(\alpha=0.62)$, seven items related to emotional control $(\alpha=0.75)$, and five items related to behavioral control $(\alpha=0.56)$, as shown in Table 1 , which also gives the means, standard errors, and standard deviations for each item in the final SRF-18 scale.

Part of the study aim was to establish SRF as a construct distinct or incremental to physical fatigue and self-control in this population. The final scale (ie, SRF-18) was moderately

Table I Factor loadings, means, and standard deviations for SRF-I8 scale items

\begin{tabular}{|c|c|c|c|c|c|c|}
\hline & & & Alpha & Mean & $\begin{array}{l}\text { Standard } \\
\text { error }\end{array}$ & $\begin{array}{l}\text { Standard } \\
\text { deviation }\end{array}$ \\
\hline & Full scale (SRF-I8) & & 0.81 & 53.77 & 0.57 & 9.90 \\
\hline & Emotional subscale & & 0.75 & 22.34 & 0.31 & 5.35 \\
\hline & Cognitive subscale & & 0.62 & 21.40 & 0.23 & 4.04 \\
\hline & Behavioral subscale & & 0.56 & 10.02 & 0.18 & 3.11 \\
\hline Item & Text & $\begin{array}{l}\text { Factor } \\
\text { loadings }\end{array}$ & Type & Mean & $\begin{array}{l}\text { Standard } \\
\text { error }\end{array}$ & $\begin{array}{l}\text { Standard } \\
\text { deviation }\end{array}$ \\
\hline 1 & I feel full of energy & 0.630 & C & 4.20 & 0.06 & 1.08 \\
\hline 2 & It's easy for me to set goals & 0.643 & C & 3.24 & 0.07 & 1.15 \\
\hline 3 & I find it difficult to exercise as much as I should & 0.500 & C & 4.07 & 0.05 & 1.17 \\
\hline 4 & I have urges to hit, throw, break, or smash things & 0.474 & B & 1.50 & 0.07 & 0.90 \\
\hline 5 & I have no trouble making decisions & 0.607 & C & 3.04 & 0.04 & 1.15 \\
\hline 6 & I experience repeated unpleasant thoughts & 0.488 & B & 2.19 & 0.07 & 1.21 \\
\hline 7 & I get easily upset & 0.760 & $\mathrm{E}$ & 2.99 & 0.07 & 1.21 \\
\hline 8 & I try not to talk or think about things that bother me & 0.493 & B & 3.12 & 0.07 & 1.12 \\
\hline 9 & I never feel like yelling, swearing, or shouting & 0.558 & $\mathrm{E}$ & 3.19 & 0.07 & 1.27 \\
\hline 10 & I handle stress well & 0.409 & $\mathrm{E}$ & 3.53 & 0.07 & 1.13 \\
\hline $\mathrm{II}$ & I experience uncontrollable temper outbursts & 0.449 & B & 1.99 & 0.58 & 1.14 \\
\hline 12 & I can easily keep up with my friendships and relationships & 0.439 & $\mathrm{C}$ & 3.13 & 0.07 & 0.15 \\
\hline 13 & I cry easily & 0.642 & $\mathrm{E}$ & 2.91 & 0.08 & 1.34 \\
\hline 14 & I have difficulties remembering things & 0.403 & C & 3.71 & 0.07 & 1.16 \\
\hline 15 & I find it easy to stick to a healthy diet & 0.489 & $\mathrm{E}$ & 3.16 & 0.07 & 1.23 \\
\hline 16 & I feel moody & 0.734 & $\mathrm{E}$ & 3.02 & 0.07 & 1.22 \\
\hline 17 & I have urges to beat, injure, or harm someone & 0.707 & B & 1.28 & 0.05 & 0.70 \\
\hline 18 & I rarely get frustrated & 0.517 & $\mathrm{E}$ & 3.54 & 0.06 & 1.07 \\
\hline
\end{tabular}

Abbreviations: B, behavioral; C, cognitive; E, emotional. 
correlated with a validated existing measure of self-control $\left(r=-0.48\right.$; Brief Self-Control Scale $\left.{ }^{18}\right)$ and highly correlated with an existing measure of fatigue $\left(r=0.75\right.$; MFSI-SF $\left.^{19}\right)$, suggesting acceptable convergent validity (see Table 2). Of note, the final scale was more highly correlated with the emotional $(r=0.72)$ and mental $(r=0.65)$ than the physical $(r=0.46)$ fatigue components of the MFSI-SF, supporting the notion that the new self-regulatory capacity scale measures a construct related to, yet likely incremental to, physical fatigue. The SRF-18 was also moderately associated with dispositional optimism $\left(r=-0.52\right.$, LOT-R). ${ }^{21}$ The final full scale is listed in Table 3.

Even though the majority of participants in this study were female, gender did not impact outcome in a statistically significant manner. Range on outcome scales was generally smaller in the male sample (SRF, 34-72 male versus 28-80 female; Brief Self-Control Scale, 21-56 male versus 24-65 female; MFSI-SF, 38-103 male versus 13-116 female; LOT-R, 13-29 male versus 6-30 female). However, the means and standard deviations were similar or slightly larger in the males, with no statistically significant difference between male $(n=19)$ and female $(n=277)$ samples.

\section{Discussion}

Recent research supports translation of the SRF construct from a laboratory paradigm to the clinical setting. Although a few studies have sought to develop self-report measures assessing self-regulation (or state ego-depletion), ${ }^{12,13}$ no established or widely used scale specifically measuring SRF exists to our knowledge at this point. The current analyses yielded a scale suggesting reliability and validity in this sample, with items reflecting overall self-regulatory capacity or SRF. Even though further research and cross-validation is necessary, such a scale could be used to research further

Table 2 Correlations with existing scales

\begin{tabular}{lllll}
\hline & SRF-I 8 & BSCS & MFSI-SF & LOT-R \\
\hline SRF-18 & - & $-0.48^{* *}$ & $0.75^{* *}$ & $-0.52^{* *}$ \\
BSCS & $-0.48^{* *}$ & - & $-0.37 * *$ & $0.36 * *$ \\
MFSI-SF (total) & $0.75^{* *}$ & $-0.37^{* *}$ & - & $-0.5 I^{* *}$ \\
$\quad$ General & $0.52^{* *}$ & $-0.20^{* *}$ & $0.85^{* *}$ & $-0.3 I^{* *}$ \\
Physical & $0.47^{* *}$ & $-0.18^{* *}$ & $0.79 * *$ & $-0.24 * *$ \\
Emotional & $0.72^{* *}$ & $-0.30^{* *}$ & $0.80^{* *}$ & $-0.59^{* *}$ \\
$\quad$ Mental & $0.65^{* *}$ & $-0.45^{* *}$ & $0.78^{* *}$ & $-0.39 * *$ \\
$\quad$ Vigor & $0.63^{* *}$ & $-0.29 * *$ & $0.76 * *$ & $-0.52^{* *}$ \\
LOT-R & $-0.52^{* *}$ & $0.36^{* *}$ & $-0.5 I^{* *}$ & - \\
\hline
\end{tabular}

Note: **Correlation significant at $P<0.01$.

Abbreviations: BSCS, Brief Self-Control Scale; LOT-R, Life Orientation TestRevised; MFSI-SF, Multidimensional Fatigue Symptom Inventory: Short Form; SRF-18, self-regulatory fatigue scale with 18 items. the role of SRF in the course of chronic illness, including treatment response and intervention.

Our results support acceptable internal consistency and reliability for the SRF-18 (Cronbach's $\alpha=0.81$ ), and the 18 final items convey a range of self-regulatory capacity, including components of cognitive, emotional, and behavioral SRF. Self-regulatory capacity or fatigue is associated with self-control as well as physical fatigue, and well established measures of these constructs (ie, the Brief Self-Control Scale and MFSI-SF) were included in the study to examine convergent validity. As expected, the SRF-18 was moderately correlated with self-control $(r=-0.48)$ and highly correlated with physical fatigue $(r=0.75)$. The SRF-18 was more significantly linked to the emotional $(r=0.72)$ and mental ( $r=0.65)$ than the physical $(r=0.46)$ fatigue components of the MFSI-SF. Recent research indicates that SRF can predict outcomes above and beyond traditional factors such as physical fatigue, ${ }^{2,11}$ and the current study supports this notion.

\section{Self-regulation as state or trait}

Self-regulatory resources likely involve state as well as trait capacity, and a new scale measuring SRF should aim to capture facets of both. State SRF is evident when higher SRF is displayed following tasks requiring self-regulatory effort, eg, attention focus. ${ }^{1}$ Trait SRF, on the other hand, might be seen through individual differences. For example, resting physiology such as heart rate variability, blood glucose, and cortisol levels have predicted later subsequent self-regulatory strength or fatigue..$^{2,6,25}$ In the current study, items related to both trait (eg, "I handle stress well" and "I rarely get frustrated") and state (eg, "I feel moody" and "I have difficulties remembering things") SRF are represented.

An assumed unrelated measure of dispositional optimism was included in the analyses aiming to establish the discriminant validity of the new scale. Rather unexpectedly, the SRF-18 correlated significantly but negatively $(r=-0.51)$ with the personality measure of dispositional optimism. Although unpredicted, these results do support recent research indicating that individual differences in personality (eg, trait optimism) may play a role in the concept or manifestation of SRF. ${ }^{26}$ However, evidence for the impact of personality on SRF is still somewhat unclear, because optimism and conscientiousness were found to be beneficial for engagement and persistence in that study only when not combined with self-regulatory effort. ${ }^{26}$ Further research examining the state versus trait aspects of self-regulatory capacity is warranted, and the SRF-18 has the potential to be of aid in this quest. 
Table 3 Final self-regulation fatigue scale (SRF-18)

\begin{tabular}{|c|c|c|c|c|c|}
\hline & \multicolumn{3}{|c|}{ Strongly disagree } & \multicolumn{2}{|c|}{ Strongly agree } \\
\hline \multicolumn{6}{|c|}{ Please indicate how much you agree with each of the following statements } \\
\hline I. I feel full of energy & 1 & 2 & 3 & 4 & 5 \\
\hline 2. It's easy for me to set goals & I & 2 & 3 & 4 & 5 \\
\hline 3. I find it difficult to exercise as much as I should & 1 & 2 & 3 & 4 & 5 \\
\hline 4. I have urges to hit, throw, break, or smash things & 1 & 2 & 3 & 4 & 5 \\
\hline 5. I have no trouble making decisions & 1 & 2 & 3 & 4 & 5 \\
\hline 6. I experience repeated unpleasant thoughts & 1 & 2 & 3 & 4 & 5 \\
\hline 7. I get easily upset & 1 & 2 & 3 & 4 & 5 \\
\hline 8. I try not to talk or think about things that bother me & I & 2 & 3 & 4 & 5 \\
\hline 9. I never feel like yelling, swearing, or shouting & 1 & 2 & 3 & 4 & 5 \\
\hline 10. I handle stress well & I & 2 & 3 & 4 & 5 \\
\hline II. I experience uncontrollable temper outbursts & 1 & 2 & 3 & 4 & 5 \\
\hline 12. I can easily keep up with my friendships and relationships & I & 2 & 3 & 4 & 5 \\
\hline 13. I cry easily & 1 & 2 & 3 & 4 & 5 \\
\hline 14. I have difficulties remembering things & I & 2 & 3 & 4 & 5 \\
\hline 15. I find it easy to stick to a healthy diet & I & 2 & 3 & 4 & 5 \\
\hline 16. I feel moody & I & 2 & 3 & 4 & 5 \\
\hline 17. I have urges to beat, injure, or harm someone & I & 2 & 3 & 4 & 5 \\
\hline 18. I rarely get frustrated & I & 2 & 3 & 4 & 5 \\
\hline
\end{tabular}

Abbreviation: SRF-18, self-regulatory fatigue scale with 18 items.

Impulse control plays an essential role in the concept of self-regulation. When capacity to self-regulate appears limited, so does ability to control impulses..$^{27}$ There has been some discussion as to whether the concept of self-regulation is simply a question of impulse control. However, although overlapping, these are distinct constructs. For example, when believing that state of affect was not changeable, no lapse in impulse control, eg, eating fatty food, seeking immediate gratification, and procrastinating, took place..$^{28}$ In chronic multisymptom illness, SRF may involve difficulties controlling impulses, such as breaking a healthy diet, but also entails challenges, such as finding it difficult to engage in interpersonal social activities. ${ }^{10}$

\section{Self-regulation and chronic illness}

Multiple factors can impact the perception and course of chronic multisymptom illness, but ability to cope with stressors may play an important role. Most active coping strategies aiming to manage or solve problems involve cognitive, emotional, or behavioral effort, and hence depend on self-regulatory strength. For example, actively trying to cope with stress has been linked with relapses for people dieting, or trying to quit smoking or drinking. ${ }^{29-33}$ Patients with chronic multisymptom illness often engage in passive coping strategies focused on avoiding or disengaging from unpleasant activities, ${ }^{34-36}$ which may be an indication of SRF, and again could explain why treatments and interventions for chronic multisymptom illnesses at times are associated with high degrees of attrition, ranging from $38 \%$ to $87 \%{ }^{37-41}$
If patients with chronic multisymptom illness are experiencing SRF due to overwhelming illness-related demands, they may not have the strength to invoke active coping strategies, or if they do, they may not have the energy to persist with such. Early detection of SRF and interventions aimed at increasing self-regulatory capacity and aid with coping are essential, ${ }^{42}$ whether such interventions build on aspects from current established therapies, such as cognitive behavioral therapy, or are developed focusing more specifically on improving self-regulatory capacity. A scale such as the SRF-18 may be of great value for clinicians and patients alike when aiming to detect and intercept SRF and improve self-regulatory capacity.

\section{Limitations and future directions}

Development of initial items for the new scale was undertaken by two researchers trained in the field of self-regulation. It would have been helpful to base item development and selection on an existing validated SRF scale developed for the general population, but because development of such scales is still at an early stage, we based item development on hypotheses and tasks from existing laboratory selfregulation studies. Future research should distribute the scale to additional samples of patients with chronic multisymptom illnesses as well as healthy participants in order to validate the scale construction further and test the scale in the general population as well as in patients with chronic or severe illness. It could also be useful to administer the scale to a sample of patients and healthy controls who are 
simultaneously undergoing laboratory self-regulation tasks to verify further the content and construct validity of the scale. Unfortunately, the laboratory paradigms generally used in healthy populations might be burdensome for populations with chronic multisymptom illnesses.

Clark and Watson ${ }^{24}$ recommended a minimum of 300 respondents be assessed at the first major stage of scale development, and factor analysis and final item selection for the study were based on responses from a sample of 296 patients diagnosed with fibromyalgia and/or chronic fatigue syndrome. The research indicates that self-regulatory capacity can be improved by practice and exercises (see Oliver et $\mathrm{al}^{40}$ for a review), perhaps even achieving less vulnerability to SRF. Considering this and the adverse effect that SRF may have on coping, quality of life, and perhaps even adherence to medical recommendations in populations with chronic illnesses, interventions improving self-regulatory capacity or decreasing SRF may be essential. Future research should therefore keep this concept in mind, assess for the degree of SRF either through laboratory experiments or selfreport measures (eg, the SRF-18), and also seek to develop and implement interventions aiming to limit or manage SRF and improve self-regulatory capacity.

\section{Conclusion}

The results of the current study support the notion that the construct of SRF translates into self-report measures in the setting of chronic multisymptom illness. The proposed self-regulation scale contains items related to cognitive, emotional, and behavioral self-regulatory control, adding to the concept of self-regulatory capacity as an ability to control internal, external, mental, and physical activities. The study also supports the notion of SRF as a related yet separate construct from physical fatigue and general self-control. A validated scale measuring self-regulatory capacity such as this has the potential to guide researchers and clinicians in how to understand better the concept of self-regulation and the impact of SRF on a variety of populations. A measurement such as the SRF-18 may also eventually contribute to a better understanding of how SRF can be detected, managed, or decreased, and aid to improve self-regulatory capacity for patients suffering from challenging conditions such as chronic multisymptom illnesses.

\section{Acknowledgments}

This research was supported in part by the Center for Translational Science Activities at the Mayo Clinic. This center is funded in part by a grant from the National Center for
Research Resources, a component of the National Institutes of Health (RR024150, to RAR). Its contents are solely the responsibility of the authors and do not necessarily represent the official view of the Center for Translational Science Activities, National Center for Research Resources, or National Institutes of Health.

\section{Disclosure}

The authors report no conflicts of interest in this work.

\section{References}

1. Baumeister RF, Bratslavsky E, Muraven M, Tice DM. Ego depletion: is the active self a limited resource? J Pers Soc Psychol. 1998;74: $1252-1265$.

2. Solberg Nes L, Carlson CR, Crofford LJ, de Leeuw R, Segerstrom SC. Self-regulatory deficits in fibromyalgia and temporomandibular disorders. Pain. 2010;151:37-44.

3. Carver CS, Scheier MF. On the Self-Regulation of Behavior. New York, NY: Cambridge University Press; 1998.

4. Higgins ET. The "self-digest": self-knowledge serving self-regulatory functions. J Pers Soc Psychol. 1996;71:1062-1083.

5. Vohs KD, Baumeister RF. Understanding self-regulation. In: Baumeister RF, Vohs KD, editors. Handbook of Self-Regulation: Research, Theory, and Applications. New York, NY: Guilford Press; 2004.

6. Segerstrom SC, Solberg Nes L. Heart rate variability indexes self-regulatory strength, exercise, and depletion. Psychol Sci. 2007;18:275-281.

7. Baumeister RF. Ego-depletion and self-control failure: an energy model of the self's executive function. Self Identity. 2002;1:129-136.

8. Muraven M, Baumeister RF. Self-regulation and depletion of limited resources: does self-control resemble a muscle? Psychol Bull. 2000;126: $247-259$.

9. Muraven M, Tice DM, Baumeister RF. Self-control as a limited resource: regulatory depletion patterns. J Pers Soc Psychol. 1998;74:774-789.

10. Solberg Nes L, Roach AR, Segerstrom SC. Executive functions, self-regulation, and chronic pain: a review. Ann Behav Med. 2009;37: 173-183.

11. Solberg Nes L, Ehlers SL, Patten CA, Gastineau DA. Self-regulatory fatigue in hematologic malignances; impact on quality of life, coping, and adherence to medical recommendations. Int J Behav Med. Epub September 18, 2011.

12. Brown JM, Miller WR, Lawendowski LA. The self-regulation questionnaire. In: VandeCreek L, Jackson TL, editors. Innovations in Clinical Practice: A Sourcebook. Sarasota, FL: Professional Resource Press; 1999.

13. Ciarocco NJ, Twenge JM, Muraven M, Tice DM. Measuring state self-control: reliability, validity, and correlations with physical and psychological stress. Presented at Monmouth University; Monmouth, NJ; eg, Harnden P, Joffe JK, Jones WG, editors. Germ cell tumours V. Proceedings of the 5th Germ Cell Tumour Conference. 2001; Sep 13-15, Leeds, UK.

14. Baumeister RF. The self. In: Gilbert DT, Fiske ST, Lindzey G, editors. Handbook of Social Psychology. New York, NY: McGraw-Hill; 1998.

15. Luedtke CA, Thompson JM, Postier JA, Neubauer BL, Drach S, Newell LA. A description of a brief multidisciplinary treatment program for fibromyalgia. Pain Manag Nurs. 2005;6:76-80.

16. Oh TH, Stueve MH, Hoskin TL, et al. Brief interdisciplinary treatment program for fibromyalgia: six to twelve months outcome. Am J Phys Med Rehabil. 2010;89:115-124.

17. Pfeiffer A, Thompson JM, Nelson A, et al. Effects of a 1.5-day multidisciplinary outpatient treatment program for fibromyalgia: a pilot study. Am J Phys Med Rehabil. 2003;82:186-191. 
18. Tangney JP, Baumeister RF, Boone AL. High self-control predicts good adjustment, less pathology, better grades, and interpersonal success. J Pers. 2004;72:271-324.

19. Stein CD, Jacobsen PB, Blanchard CM, Thors C. Further validation of the multidimensional fatigue symptom inventory-short form. J Pain Symptom Manage. 2004;27:14-23.

20. Stein KD, Martin SC, Hann DM, Jacobsen PB. A multidimensional measure of fatigue for use with cancer patients. Cancer Pract. 1998;6: 143-152.

21. Scheier MF, Carver CS, Bridges MW. Distinguishing optimism from neuroticism (and trait anxiety, self-mastery, and self-esteem): a reevaluation of the Life Orientation Test. J Pers. 1994;67:1063-1078.

22. Gorsuch RL. Factor Analysis. Hillsdale, NJ: Erlbaum; 1983.

23. Lee HB, Comrey AL. Distortions in a commonly used factor analytic procedure. Multivariate Behav Res. 1979;14:301-321.

24. Clark LA, Watson D. Constructing validity: basic issues in objective scale development. Psychol Assess. 1995;7:309-319.

25. Gailliot MT, Baumeister RF, DeWall CN, et al. Self-control relies on glucose as a limited energy source: willpower is more than metaphor. J Pers Soc Psychol. 2007;92:325-336.

26. Solberg Nes L, Carlson CR, Crofford LJ, de Leeuw R, Segerstrom SC. Individual differences and self-regulatory fatigue: optimism, conscientiousness, and self-consciousness. Pers Individ Dif. 2011;50: 475-480.

27. Baumeister RF, Heatherton TF, Tice DM. Losing control: how and why people fail at self-regulation. San Diego, CA: Academic Press; 1997.

28. Tice DM, Bratslavsky E, Baumeister RF. Emotional distress regulation takes precedence over impulse control: if you feel bad, do it! J Pers Soc Psychol. 2001;80:53-67.

29. Cohen S, Lichtenstein E. Perceived stress, quitting smoking, and smoking relapse. Health Psychol. 1990;9:466-478.

30. Doherty K, Kinnunen T, Militello FS, Garvey AJ. Urges to smoke during the first month of abstinence: relationship to relapse and predictors. Psychopharmacology. 1995;119:171-178.

31. Hodgins DC, el Guebaly N, Armstrong S. Prospective and retrospective reports of mood states before relapse to substance use. J Consult Clin Psychol. 1995;63:400-407.
32. Wadden TA, Letizia KA. Predictors of attrition and weight loss in patients treated by moderate and caloric restriction. In: Wadden TA, VanItallie TB, editors. Treatment of the Seriously Obese Patient. New York, NY: Guilford Press; 1992.

33. Wevers ME. The role of postcessation factors in tobacco abstinence: stressful events and coping responses. Addict Behav. 1988;13: 297-302.

34. Callahan CD. Stress, coping, and personality hardiness in patients with temporomandibular disorders. Rehabil Psychol. 2000;45:38-48.

35. Ferrando M, Andreu Y, Galdon MJ, Dura E, Poveda R, Bagan JV. Psychological variables and temporomandibular disorders: distress, coping, and personality. Oral Surg Oral Med Oral Path Oral Radiol Endod. 2004;98:153-160.

36. Zautra AJ, Hamilton NA, Burke HM. Comparison of stress responses in women with two types of chronic pain: fibromyalgia and osteoarthritis. Cognit Ther Res. 1999;23:209-230.

37. Martin MY, Bradley LA, Alexander RW, et al. Coping strategies predict disability in patients with primary fibromyalgia. Pain. 1996;68: 45-53.

38. Mengshoel AM, Komnaes HB, Forre O. The effects of 20 weeks of physical fitness training in female patients with fibromyalgia. Clin Exp Rheumatol. 1992;10:345-349.

39. Norregaard J, Lykkegaard JJ, Mehlsen J, Danneskiold-Samsoe B. Exercise training in treatment of fibromyalgia. J Musculoskelet Pain. 1997;5:71-79.

40. Oliver K, Cronan TA, Wahlen HR. A review of multidisciplinary interventions of fibromyalgia patients: Where do we go from here? J Musculoskelet Pain. 2001;9:63-80.

41. Wigers SH, Stiles TC, Vogel PA. Effects of aerobic exercise versus stress management treatment in fibromyalgia. Scand J Rheumatol. 1996;25:77-86.

42. Baumeister RF, Gailliot M, DeWall CN, Oaten M. Self-regulation and personality: how interventions increase regulatory success, and how depletion moderates the effects of traits on behavior. J Pers. 2006;74:1773-1801.
Journal of Pain Research

\section{Publish your work in this journal}

The Journal of Pain Research is an international, peer-reviewed, open access, online journal that welcomes laboratory and clinical findings in the fields of pain research and the prevention and management of pain. Original research, reviews, symposium reports, hypothesis formation and commentaries are all considered for publication.

\section{Dovepress}

The manuscript management system is completely online and includes a very quick and fair peer-review system, which is all easy to use. Visit http://www.dovepress.com/testimonials.php to read real quotes from published authors. 